\title{
História Social \\ da Guerra do Paraguai:
fome, doencas e penalidades
}

Maria Teresa Garritano Dourado*

A proposta desse trabalho é analisar a Guerra do Paraguai sob um novo olhar, sob o ângulo do soldado comum que, muitas vezes, arrastado para as batalhas, teve que lutar principalmente pela sobrevivência e, na maioria das vezes, morrer. Trata-se aqui de dar visibilidade aos horrores que passaram os soldados e marinheiros, subnutridos e enfraquecidos pela falta de alimentos e por isso mais sujeitos às doenças, Analiso, também, o funcionamento da Justiça Militar em um acampamento do exército brasileiro e em navios da armada imperial onde se vivia sob indispensáveis regras disciplinares, muitas vezes quebradas.

Palavras-chave: fome, doenças e penalidades.

The purpose of this work is to analyze the War of Paraguay under a new look from the perspective of the ordinary soldier who often drawn into the battles, mainly had to fight for survival and, in most cases, die. It is here to give visibility to the horrors that have passed the soldiers and sailors, malnourished and weakened by lack of food and therefore more subject to diseases, analyze also the functioning of military justice in an army camp in Brazil and ships where the imperial army was under disciplinary rules indispensable, often broken.

Keywords: disease, hunger and crime.

\begin{abstract}
A História da Guerra do Paraguai pode ser contada em paralelo à história das doenças infecciosas como dois temas que se sobrepõem, caminhando juntas e interferindo nas ordens de comando dos acampamentos militares. A doença deixou de ser um objeto exclusivo da Medicina e passou a ser problematizada pela História.

Os germens, os inimigos, a dor e a morte conviviam no mesmo campo de batalha e competiam pela sobrevivência.
\end{abstract}

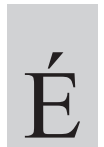

claro que se deve considerar que a presença de enfermidades nos campos de batalhas foi também o produto das extremas condições de vida, das exposições de soldados e civis ao clima, da falta de medicamentos, de alimentos; que causou desnutrição e, portanto, propensão a doenças, assim como outras carências que se impuseram durante a guerra. A aparição de pestes tampouco pode atribuir-

\footnotetext{
* Prof ${ }^{a}$ Doutora em História Social pela Faculdade de Filosofia, Letras e Ciências Humanas - USP. .ts.dourado@uol.com.br
} 
-se à casualidade. A escassa alimentação, os milhares de cadáveres insepultos, as más condições higiênicas, a enorme quantidade de bactérias que assolavam o acampamento e campos de batalha contribuíram para a imensa mortandade que existiram durante a campanha. A longa lista de motivos para a expansão de enfermidades e pestes deve juntar-se ao grave dano do sistema ecológico e ao equilíbrio natural que se efetuou com a presença de grande quantidade de pessoas que se deslocavam incessantemente pelos pântanos, pelas matas e bosques, penetrando no habitat natural dos agentes transmissores de doenças.

Uma das principais referências para o estudo das doenças na guerra são os diários dos soldados e dos viajantes, muitos dos quais personagens de suas próprias narrativas, que enriquecem o conteúdo da documentação médica porque são testemunhas oculares que vivenciaram a dor, o desespero e o medo diante da morte. Os diários escritos nos acampamentos revelam situações nem sempre anotadas pelos registros médicos, que também são fontes valiosas e descrevem um quadro minucioso dos sintomas das doenças, que muito contribuem para esclarecer certas enfermidades e possibilitam um cotejamento entre algumas questões: tratamento dos doentes, condições higiênicas e sanitárias, sintomatologia das doenças, e muitos outros problemas que o cotidiano de um acampamento militar proporciona.

As memórias dos veteranos dos países envolvidos oferecem subsídios para uma análise da qualidade do serviço médico, dos alimentos disponíveis, das doenças e muitos outros assuntos referentes à campanha, destacando-se que esses documentos revelam uma riqueza de detalhes ajudando a desvendar o passado, lançando luz e permitindo perceber uma história dos indivíduos e estudar o seu dia a dia. Bastante elucidativos são os escritos de Alfredo d'Escragnolle Taunay, André Rebouças, Augusto Tasso Fragoso, Carlos Frederico dos Santos Xavier Azevedo Evangelista de Castro Dionísio Cerqueira, Francisco Pereira da Silva Barbosa, George Frederick Masterman, George Thompson, João Pedro Gay, Juan Crisóstomo Centurión, José Luiz Rodrigues da Silva, Leon de Palleja, Luiz de Castro Souza, Louis Schneider, Manoel Carneiro da Rocha e Richard Burton, entre muitos outros, e todos eles sem exceção descrevem os próprios padecimentos e o cotidiano de um soldado com riqueza de detalhes.

Nos registros de doenças dos Livros de Hospitais e Enfermarias, bem como nos atestados de óbito, anotavam-se os diagnósticos prováveis como diarreias, 
disenteria, febres e mal das urinas, entre outros, confundindo o diagnóstico das doenças e certamente a forma de como tratá-las. Também em diários era comum a denominação de doenças pelos seus sinais apresentados e pela sintomatologia. ${ }^{1}$

Parte dos soldados feridos e doentes era deixada, em convalescença, em várias localidades portuárias ou em enfermarias localizadas próximo aos acampamentos. Além das questões sanitárias, sempre presentes na mobilização e até mesmo na desmobilização, é possível deduzir quando se lê a documentação disponível, que as unidades, desde o início da guerra, não tinham a sua disposição barracas adequadas e suficientes e nos navios espaços que lhes permitissem uma qualidade de vida saudável ${ }^{2}$.

“A peste é a maior inimiga que temos”, em oficio do mês de julho de 1865 ao Ministro da Guerra Ângelo Muniz da Silva Ferraz, o Marechal de Campo Manuel Luis Osório, demonstrava preocupação com o estado sanitário do exército brasileiro ${ }^{3}$. Assumiu um exército em precárias condições no dia $1^{\circ}$ de março de 1865, quando o General João Procópio Menna Barreto, sofrendo de tuberculose em estado avançado, retirou-se para o Rio Grande do Sul ${ }^{4}$. Essa tropa, cujo efetivo era de 9.465 homens, acampado próximo a Montevidéu, tinha no seu Corpo de Saúde 17 pessoas responsáveis pela assistência médico-cirúrgica, muitas delas sem preparo para enfrentar as situações médicas que exigiam uma atuação de guerra. Fatigada por longas marchas, a tropa sofria com o calor excessivo e o frio intenso, com as condições higiênicas e sanitárias, devido à utilização de água poluída, que causava enfermidades e com a mudança completa do regime alimentar a que estavam acostumados e que os enfraquecia e debilitava. A diarreia e a disenteria com poder devastador foram as causadoras de muitas mortes e responsáveis pela baixa de milhares de combatentes, tanto brasileiros como paraguaios, argentinos e uruguaios. Esses males grassaram durante toda a guerra com maior

${ }^{1}$ ROCHA, M. C. Diário da campanha naval do Paraguai, 1866. Rio de Janeiro: Serviço de Documentação da Marinha, 1999, p. 1.

${ }^{2}$ PRATA, S. J. As condições sanitárias e higiênicas durante a Guerra do Paraguai. In: NASCIMENTO, D. R.; CARVALHO, D. M. (Org.). Uma história brasileira das doenças. Brasilia: Paralelo 15,2004 , p. 61.

${ }^{3}$ OSÓRIO, J. L.; OSÓRIO FILHO, F. L. História do general Osório. Pelotas, RS: Typ. do Diário Popular, 1915, p. 93.

${ }^{4}$ SILVA, J. L. R. Recordações da campanha do Paraguay. São Paulo: Melhoramentos, s.d., p/13. 
ou menor intensidade 5 , tendo ainda o agravante de que parte dos recrutas já chegava doentes ao cenário da batalha, transmitindo e disseminando as doenças de suas cidades de origem onde as epidemias foram frequentes em todo o período colonial. Em São Francisco e Dayman, nas proximidades de Salto, um veterano narrou: "Ahi registramos baixas enormes, e os cemitérios atulharam-se, causava lastima, ver como a desynteria ceifava impiedosamente." ${ }^{6}$ Mas naquela época o termo disenteria poderia significar um número muito grande de doenças, como parasitose e tifo entre muitas outras. $\mathrm{O}$ mesmo veterano descreveu corroborado por outro, algumas tentativas, entre outras que se faziam em todos os exércitos para debelar as doenças, mas que com o tempo se mostraram infrutíferas:

Começando a grassar a desynteria, de modo assustador, e, attibuindo-se ao facto da distribuição da carne no momento de abatido o gado, este serviço passou a ser feito com antecedencia de 12 horas, cessando o mal em erupção, para reapparecer mais tarde, transformado em cholera-morbus asiatico, bexiga pelle de lixa, typho e sarampo, tudo a um tempo ${ }^{7}$. Desde o momento em que a cólera apareceu, houve ordem para que se fizessem, por todo o acampamento, fumigações com folhas de louro e capim, e o quartel-general estava tão continuamente impregnado de fumaça que era quase impossível morar-se lá. López compreendeu sua total impotência para lutar pessoalmente contra tão terrível flagelo, e ficou quase louco, acusando seus médicos de intenção de matá-lo, sendo sua denuncia secundada pelo bispo ${ }^{8}$.

Provavelmente o uso de fumaça com folhas medicinais pelo exército paraguaio provém da orientação de médicos estrangeiros que compunham a equipe de saúde de Solano López, muito comum em outros países europeus, como durante a epidemia de cólera em Granada, 1865, quando a teoria dos miasmas ainda dominava. Os moradores acendiam fogueiras pelas ruas na tentativa de purificar o ar ou afastar as substâncias nocivas que este continha ${ }^{9}$. Até então, a causa das doenças transmissíveis continuava um mistério: falava-se no miasma, a emanação de regiões insalubres (o termo malária, "maus ares", alude precisa-

\footnotetext{
${ }^{5}$ THOMPSON, G. Guerra do Paraguai. Rio de Janeiro: Conquista, 1968, p. 95.

${ }^{6}$ SILVA, J. L. R. Op. cit., p. 27.

${ }^{7}$ Idem, p. 50.

${ }^{8}$ THOMPSON, G. Op. cit., p. 164.

${ }^{9}$ UJVARI, S. C. A história e suas epidemias: a convivência do homem com os microorganismos. Rio de Janeiro: Senac Rio, 2003, p. 137.
} 
mente a isso). Pela teoria dos miasmas, os locais imundos, contendo dejetos de lixo orgânico em decomposição, emanavam substâncias invisíveis, mas nocivas e causadoras das doenças infecciosas e epidemias, impregnando o ar. Portanto, contraía-se a infecção ao respirar o ar que continha tais substâncias miasmáticas, e não pelo contágio de pessoa a pessoa. A teoria já era antiga, haja vista que se supunha que a malária provinha do mau cheiro dos pântanos. Os miasmas, porém, ganharam mais importância no século XIX ${ }^{10}$.

Enquanto a teoria dos miasmas dominava a mentalidade européia, cresciam os indícios da outra forma de aquisição das infecções, o contágio, uma teoria que se opunha à primeira. O contágio acarretaria a disseminação das infecções por meio do contato direto de pessoa para pessoa, ou por meio de objetos contaminados pelo doente. Apesar de essa tese ser a correta, a teoria dos miasmas dominava o terreno científico. Seriam necessárias seguidas descobertas futuras para que essa teoria fosse ganhando terreno até, finalmente, ter a sua consagração com a identificação dos agentes causadores das infecções, os germes.

Vale ressaltar que muitos soldados davam parte de doenças para poderem fugir das batalhas, fato amplamente comprovado pelas fontes. O número de doentes que permaneciam nos hospitais e enfermarias aponta para outro problema que foi a disponibilidade de praças enviados para as frentes de batalha, condicionando assim planos de guerra ao número de doentes.

Em uma de suas Exposições, o Alferes do $5^{\circ}$ Regimento de Cavallaria Ligeira Francisco de Assis Trajano de Menezes, Ajudante de Campo do General Osório, escreveu do teatro de operações alguns tópicos, onde se pode observar um panorama geral das diversas dificuldades em que se encontrava o exército brasileiro, entre eles:

O Exercito nesse dia, não passava de um chão de calamidades. A soldadesca nua, a officialidade desgostosa em conseqüência da Ordem do Dia n ${ }^{\circ} 17$ que publicou o combate de Paysandú. Uns, pedindo justiça pelo desprezo ou olvido a que foram atirados os seus serviços; outros, inspeccionando-se de saúde e fazendo-se julgarem-se inválidos; muitos pediram licença; enfim, a magua, o descontentamento era o que se manisfestavam desde os soldados até aos officiaes superiores. Chegavam ao campo, logo encontravam o frio que

${ }^{10}$ CHAlHOUB, S. Cidade fabril. Coretiço e epidemias na corte imperial. São Paulo: Cia. Das letras, 2004, p. 64/65. 
os congelava, a differença na alimentação, outra maneira de vida, a varíola que assolava as febres; emfim, muitos não sobreviveram a taes rigores. Um Batalhão do Pará que o Ministro da Guerra recommendára ao General como de nadadores e mesmo de um pessoal robusto, em poucos dias tão dizimado ficou, que o General teve que dissolvel-o, mandando para outro Batalhão o seu commandante que era um tenente commissionado no posto de Tenente-Coronel e alguns poucos officiaes que resistiram as intempéries ${ }^{11}$.

Tudo leva a crer que as doenças visíveis como cólera, varíola e malária que matavam com muito mais rapidez e eram em maior número foram contabilizadas, enquanto que outras doenças como, por exemplo, as sexuais, entre outras, que demoravam levar a morte muitas vezes passavam despercebidas no campo de guerra e não foram diagnosticadas e tratadas. É preciso ressaltar que os termos febres e sintomas febris foram bastante utilizados naquela época em que os diagnósticos das doenças eram muitas vezes imprecisos e inexistentes. A maioria dos estudiosos que se refere ao número de vítimas de combatentes e populações civis que pereceram na Guerra do Paraguai, não só no exército aliado, mas também entre os paraguaios, concorda, ao menos, em uma coisa: que mais gente morreu como conseqüência das enfermidades, fome e pestes do que por ações bélicas em $\mathrm{si}^{12}$. Tal hipótese procede, pois grande parte da documentação disponível nos arquivos públicos, no Brasil e no exterior, possibilita a investigação sobre os numerosos hospitais e enfermarias bem como, na falta deles, era o atendimento aos soldados feridos e doentes.

Seis meses depois de iniciada a luta, o Império do Brasil ainda não tinha conseguido começar a defensiva e em 21 de maio de 1866, portanto, há mais de um ano em que o General Osório comandava as tropas aliadas, as doenças ainda eram as responsáveis pela maioria das mortes dos soldados cujas perdas somavam 10.400 homens $^{13}$.

Reconheço que há um grande numero de doentes. Isto porem, se explica pela natureza insalubre do clima, e das circunstancias do nosso Exercito exposto muitas vezes ás intempéries atmosphericas e ás duras fadigas da guerra. Digo a V. Ex. que si nos demorarmos muitos mezes entre tantos pântanos sem água potável e no meio de tantos animaes mortos, o numero de doentes será inde-

\footnotetext{
${ }^{11}$ OSÓRIO, J. L.; OSÓRIO FILHO, F. L. Op. cit., p. 82.

12 ARQUIVO DA MARINHA. Relatório do Ministério e Secretaria de Estado da Marinha, 1870. ${ }^{13}$ OSÓRIO, J. L.; OSÓRIO FILHO, F. L. Op. cit., p. 254.
} 
terminado, sem que a grande solicitude de V. Ex. e os esforços dos medicos possam pôr termo a isto ${ }^{14}$.

Mas a partir da administração do exército pelo General Caxias, em 1867, houve um cuidado mais acentuado na hospitalização, ambulâncias e higiene na alimentação, vestuário apropriado, abrigo da tropa e asseio dos acampamentos. A morte por afogamentos, suicídios, doenças venéreas, pneumonia, lepra, raios, varíola, sarampo, impaludismo, diarreia, disenteria, tifo, cólera, sífilis, beribéri, tuberculose, insolação e febres malignas rapidamente disseminadas durante a guerra devido ao deslocamento de soldados, migrações de populações refugiadas e aos estupros da população feminina, ocasionaram uma mortandade nunca vista antes em campos de batalha e "causavam mais mortes que a metralha paraguaia." 15 Não há estimativa unânime entre os pesquisadores que quantifique o número de mortos no fim da guerra, da população civil e militar, assim como não há consenso sobre o número de mortos por doenças epidêmicas e por ferimentos recebidos nas batalhas. Os soldados desmobilizados e enviados de volta ao Brasil para tratamento médico, devido às doenças crônicas ou mutilações de seus membros inferiores e superiores, tornaram-se um problema social, grave, para ser resolvida pela administração pública. Eles ficaram conhecidos como os "inválidos da pátria."16

Nos acampamentos militares e nos navios da armada imperial, onde conviviam milhares de homens, mulheres e crianças, tornou-se indispensável adotar medidas que garantissem as mínimas condições higiênicas. Muitos documentos indicam a preocupação das autoridades com a falta de asseio, demonstrando que já havia a percepção e o conhecimento que ligavam as condições sanitárias e as doenças, alertando para a limpeza dos respectivos acampamentos e navios. Determinavam a necessidade de enterrar diariamente a uma distância conveniente os resíduos e outros materiais suscetíveis de infecção e transmissão de inúmeras doenças, bem como a queima de todo o material usado pelos doentes coléricos,

\footnotetext{
${ }^{14}$ Idem, p. 255.
}

${ }^{15}$ CERQUEIRA, E. C. D. Reminiscências da campanha do Paraguai, 1865 - 1870. Rio de Janeiro: Bib. do Exército, 1929, p. 46.

${ }^{16}$ GOMES, M. A. M. A espuma das províncias: um estudo dos inválidos da patria e o asilo dos inválidos da patria, na corte (1864 - 1930). Tese Doutorado em História. - Faculdade de Filosofia, Letras e Ci6encias Humanas, USP, 2006, p. 04. 
principalmente na estação quente quando as doenças eram mais aceleradas pela ação do calor:

Commando em Chefe de todas as forças brazileiras em operações na República do Paraguay. Quartel General em Tuipi-cue, 4 de setembro de 1867. Ordem do Dia N. 121. A despeito das repetidas recomendações que tem sido feitas acerca do asseio do acampamento continua elle a não estar convenientemente limpo, existindo por enterrar muitos animaes mortos. Manda chamar de novo a attenção dos encarregados deste ramo de serviço, que torna-se urgentíssimo, attenta a estação calorosa em que entramos e as enfermidades que podem originar-se dessa falta de asseio. O Coronel João de Souza Fonseca Costa. Chefe do Estado Maior arquivo do Exercito. Expeça V. Ex. as necessárias ordens para que os Srs. commandantes dos navios de guerra, logo que se dê a bordo o fallecimento de qualquer praça affetada do cholera morbus, mandem consumir os colchões, roupas e utensílios de que se tiverem ellas servido, procedendo-se imediatamente á desinfecção possível, a qual se completará com todos os meios que aconselha a sciencia, assim que o navio fundeie. Affonso Celso de Assis Figueiredo. Sr. Chefe da Esquadra encarregado do Quartel Geral da Marinha $^{17}$.

De fato, orientados pelo conhecimento científico da época e sabedores que a bactéria causadora da infecção intestinal era eliminada pela diarreia no meio ambiente, contaminando a água e alimentos ingeridos pelos soldados e fazendo com que a doença se alastrasse, os comandantes dos vários exércitos e navios emitiam ordens do dia determinando procedimentos para efetuar a limpeza de acampamentos e navios militares. Tarefa difícil de executar diante do número de soldados confinados em navios, acampamentos insalubres, da rapidez da contaminação, diagnóstico e conseqüente morte, pois o contato de pés e mãos com objetos ou substâncias contaminadas pelas bactérias e a relação próxima dessas mãos com a de outros soldados e com alimentos levados à boca provocavam rapidamente a diarréia. $\mathrm{O}$ modo preferencial de transmissão se fazia através de ingestão de água ou alimentos contaminados por fezes ou vômitos de doente.

"A cólera era mais terrível do que os milheiros de Lopez"18 e dizimou os batalhões de soldados, ceifando vidas aos montões. Foi a doença que mais causou vítimas entre os combatentes da Guerra do Paraguai. Embora decorridos

\footnotetext{
${ }^{17}$ ARQUIVO DA MARINHA. Copilação das Ordens Gerais, 1866 - 1868. Ordem Geral, n. 2, v. 5. ${ }^{18}$ CERQUEIRA, E. C. D. Op. cit., p. 192.
} 
dez anos da terrível epidemia de cólera na Bahia de onde provinha boa parte dos soldados, a burocracia e a medicina ainda não haviam alcançado avanços significativos que pudessem curar a doença ou minimizar os sofrimentos dos soldados infectados e mesmo deter a marcha das epidemias nos acampamentos ${ }^{19}$. Nesse contexto epidêmico urbano, os soldados que saíam das várias regiões do Brasil para combater na guerra e sem uma política de prevenção e meio eficazes para isolar os doentes, espalhavam as doenças em todo o cenário da guerra.

Dentre as várias enfermidades que assolavam os campos de batalha e navios nenhuma delas causou mais medo e pavor que a varíola, perseguindo os soldados durante toda a campanha contra o Paraguai. Quase não havia uma política de prevenção e vacinação que se mostrasse eficiente e capaz de evitá-las, situação extremamente difícil de resolver porque em um exército em constante movimento saber onde houve a contaminação era quase impossível. Ressaltando que numa epidemia um único caso pode se alastrar, contaminando milhares de pessoas, e que o período de incubação de determinada doença pode variar em vários dias.

Por longos períodos e por vários motivos houve resistência à vacina, perdurando até o século $\mathrm{XX}$, por ocasião da divulgação do projeto de regulamentação da lei que tornara obrigatória a vacinação e que transformou a cidade do Rio de Janeiro em praça de guerra, em novembro de 1905, com a conhecida Revolta da Vacina. Embora a vacinação tenha obtido repercussão mundial, espalhando-se pela Europa, a resistência a ela foi muito grande: o método utilizado poderia, entre alguns casos, causar o desenvolvimento da doença em pessoas que a recebiam precipitando o surgimento de epidemias, levando à morte por erisipelas, pois as lesões que ocorriam no braço inoculado eram grandes e profundas e, muitas vezes infectavam. Só em 1887 é que foi introduzida a vacina animal, importada pelo Barão Pedro de Afonso Franco, fundador do primeiro Instituto Vacinogênico do país, no Rio de Janeiro. Sidney Chalhoub esclareceu muitos pontos importantes como, por exemplo, a rejeição da população à vacina, pois sentiam verdadeiro horror ${ }^{20}$ enfatizados por artigos em jornais que afirmavam haver o risco de transmissão da sífilis e outras doenças através da vacinação. Ele esclarece, em sua análise, que "a

${ }^{19}$ DAVID, O. R. O inimigo invisível: a epidemia de cólera na Bahia em 1855 - 1856. Dissertação (Mestrado), 1994, p.85.

${ }^{20}$ CHALHOUB, S. Op. cit., p. 113. 
vacina não garantia imunização permanente já que havia muitos casos da ocorrência de varíola em vacinados." ${ }^{21} \mathrm{O}$ método de vacinação efetuado nessa época, braço a braço, e a forma como o serviço estava estruturado na Corte foram responsáveis pela resistência da população e certamente muitos soldados se negavam a tomá-la apesar de existir uma ordem para se vacinarem. Os próprios vacinadores, não obedeciam ou questionavam para irem até os quartéis vacinar os recrutas que estavam de partida para o Paraguai ${ }^{22}$.

A varíola (do inglês small-pox), vulgarmente conhecida como bexiga ou febre eruptiva, constituiu outrora uma das mais temíveis pestes que assolaram a humanidade, devido a sua extrema contagiosidade e alta letalidade. Em latim, a palavra vari significa "irrupção de botões"; varius são "indivíduos com o rosto recoberto de manchas". Os acometidos tinham a face com aspecto salpicado bariolado, variolado pela doença. ${ }^{23}$

No cenário da guerra os doentes eram levados aos hospitais em carretas cobertas de couro, deitados sobre pelego de carneiros. Contaminados de pus varioloso, ficavam disformes com a doença, o rosto enorme inchado e cheios de pústulas denegridas, que exalavam cheiro nauseabundo. Os doentes "bexiguentos" cresciam em número, tanto pelo frio como pela disseminação de outras doenças como o sarampo, que foi importado pelas forças vindas da Corte. O General Osório solicitou a remessa de mais médicos e lembrou ao Ministro da Guerra a conveniência de virem os soldados vacinados da Corte ou das suas províncias $^{24}$.

São raros os documentos relatando a preocupação com a vacinação. Os seguintes são quase uma exceção:

Quartel General do Commando em Chefe do Exercito em operações, acampamento junto a Lagoa Brava, em 9 de Janeiro de 1866. Ordem do Dia N.116. O Exmo. Sr. General Commandante em Chefe, manda louvar e agradecer o relevante serviço que prestou ao Exercito, o Sr. Major Manoel Ignácio da

${ }^{21}$ Idem, p. 118.

${ }^{22}$ VOLPATO, L. R. R. Cativos do sertão: vida cotidiana e escravidão em Cuaibá (1850 - 1888). São Paulo: Marco Zero, 1883, p. 71/81.

23 UJVARI, S. C. Op. cit., p. 129.

${ }^{24}$ Idem, P. 61. 
Silva, commandante do $1^{\circ}$ Corpo Provisório de Cavallaria da Guarda Nacional, o qual mostrou tal interesse e solicitude pela saúde e conservação de seus comandados que, por sua expontanea deligencia alcançou o púz vaccinico, com que não só vaccinou grande numero de seus praças, que ainda o precisavão, como o que nas mesmas circumstancias se achavão em todos os outros corpos de Cavallaria e d' alguns de Infantaria, sendo a elle sómente devida a semente de que dispomos para a vaccinação dos poucos praças dos corpos ultimamente chegados, que precisão ainda do mesmo preservativo. $\mathrm{O}$ mesmo Exmo. Sr. General, informado do interesse humanitário e zelo com que se tem desenvolvido o Sr. $2^{\circ}$ Cirurgião Dr. Firmino José Dona, não só no serviço de Infantaria a seu cargo, como na vaccinação dos praças do exercito ainda não garantidas por este preservativo, da peste de varíola, manda igualmente louval-o por tão importante serviço. Innocencio Velloso Pederneiras Tenente-Coronel ${ }^{25}$. Grassando a bexiga no Vapor Princesa, determinou o Almirante que fossem conduzidos a Buenos A ires os doentes no Vapor Imperatriz, acompanhados pelo médico do Exército, que de cima vinha vindo, no mesmo vapor ${ }^{26}$.

No Brasil, a campanha de vacinação era agravada pela falta de recursos; as pústulas saíam caro porque eram importadas da Europa. A dificuldade de transportes para províncias distantes e o fato de a vacina não garantir a completa imunização despertaram um alto índice de desconfiança por parte da população, que não acreditava nela, produzindo estratégias para fugir das autoridades do governo $^{27}$. De fato, milhares de soldados foram para a guerra sem serem vacinados o que ocasionou uma mortandade nunca vista nos campos de batalha e navios da armada imperial.

Não havia, ao começar a Guerra do Paraguai, instrumental médico, hospitalar e cirúrgico, nem ambulâncias. $O$ pessoal médico não tinha experiência suficiente com respeito ao tratamento de feridas e a técnicas cirúrgicas, que se reduziam a extrair balas, amputar braços e pernas procedimentos realizados pelos médicos veteranos e alunos de medicina ${ }^{28}$. O serviço de saúde do exército brasileiro durante a guerra era precário, deficiente e a falta de assepsia fez com

\footnotetext{
${ }^{25}$ ARQUIVO HISTÓRICO DO EXÉRCITO. Ordens do dia. Ordem n. 116- Osorio 2º

${ }^{26}$ ROCHA, M. C. Op. cit., p. 90.

${ }^{27}$ SOUSA, J. L. P. Campanha da vacinação contra a variola durante a Guerra contra o Paraguai, 1865 - 1870. ANPUH, 2009, p. 325.

${ }^{28}$ GOMES, M. A. M. Op. cit., p. 245-294.
} 
que raramente escapasse da morte quem tivesse que amputar um braço ou uma perna $^{29}$.

Os meios terapêuticos para evitar os riscos de afecções agudas eram reduzidos e poucos eficazes. Para tudo se aplicavam as difundidas sangrias e os purgantes, com a idéia de que purificavam o sangue. A sangria, procedimento largamente utilizado desde o século XVI, inicialmente pelos jesuítas e depois também pelos boticários e cirurgiões, é assim relatada:

A sangria ou sanguilexia, foi a panacéia universal dos séculos passados. Por meio dela retirava-se a causa da doença, retirava-se o humor vicioso, o humor podre, o humor colérico, o humor fleumático, o humor melancólico, e até mesmo o excesso do próprio humor sanguíneo. Sangrar e purgar tal foi, em resumo, a orientação terapêutica, seguido por todos, em quase todas as doenças, notadamente contra as febres. (...) E segundo os preceitos hipocráticos, sangraram sempre os mais próximo do loco dolenti - local. ${ }^{30}$

Os mesmos medicamentos eram receitados para doenças diferentes, medicavam-se com o mesmo remédio os apoplécticos, para curar o tifo e a disenteria $^{31}$. Também eram usados uma dose de sal amargo e de vinho do Porto no caso de perda de muito sangue. Dr. João Severiano da Fonseca, cirurgião do regimento, ao atender um ferimento na cabeça, cheirou a ferida e "afirmou não ser de bala porque não cheirava a chamusco"32.

O Corpo de Saúde, escandalosamente deficiente, contava até com estudantes do $1^{\circ}$ ano das escolas de medicina, que seguiam para a campanha contratados, às vezes, com salários superiores aos dos médicos antigos do quadro, e desempenhavam trabalhos de alta cirurgia, "empunhando um ferro com a maior sem cerimônia, cortando, retalhando a carne humana, desalmadamente."33

Os profissionais médicos, poucos para atenderem milhares, não estavam capacitados para enfrentar as situações que se apresentaram durante a campanha. Lutavam contra a falta de recursos materiais, a falta de conhecimento de

\footnotetext{
29 SILVA, J. L. Op. cit., p. 113.

30 SANTOS FILHO, L. História geral da medicina brasileira. São Paulo: USP, 1977, v. 1, p. 229.

${ }^{31}$ CERQUEIRA, E. C. D. Op. cit., p. 52.

32 Idem, p. 114.

${ }^{33}$ SILVA, J. L. Op. cit., p. 114.
} 
algumas doenças, o seu próprio despreparo devido à inexperiência no tratamento de ferimentos e epidemias e a falta de qualificação de seus ajudantes. Sobre a perplexidade dos médicos, diante de tantas epidemias, narrou Taunay: "os médicos, alias, bastante ignorantes, mostravam-se atônitos e não ousavam decidir, receitando as tontas e com incoerência e falta de lógica dignas de lástimas." ${ }^{34}$ Num documento reservado, do dia 8 de junho de 1866, foi comunicado ao Gabinete do Ministro que os abusos dos médicos eram cometidos com freqüência e denunciados: "Constatou-se que no Hospital de Saladeiro se dão enormes abusos, que longe de aliviar, aggavão as circunstâncias dos infelizes que no serviço da Pátria sacrificavão sua saúde e se achão em tratamento. Constatou-se mesmo que a falta de caridade tem chegado a ponto de o Dr. Francisco Mendes de Amorim castigar com bolas, e mandar carregar com armas e saccas d'areia as praças enfermas." 35

Com poucas alternativas para tratamento, os médicos aconselhavam o álcool como profilático, um mau costume daquela época, quando muitos se tornavam alcoólatras, porque se acreditava na profilaxia do álcool contra as febres palustres e outras enfermidades ${ }^{36}$. O local para onde eram levados os doentes e feridos foi relatado por muitos com repulsa e horror: "Os chamados hospitais de sangue, espaços tristes, sombrios e fúnebres, nada mais eram que pobres ranchos, cobertos de palha, sempre cheios de feridos, que chegavam estropiados, ensanguentados, em doloroso desalinho; uns sozinhos; outros se apoiando em camaradas com ferimentos menos graves; a maior parte carregada no ombro, em redes feitas de capotes e mantas. ${ }^{\prime 37}$

Rodrigues da Silva, veterano da guerra, referiu-se muitas vezes ao que viu, no hospital central do exército: barraquinhas mal armadas, de porta aberta, soldados doentes deitados em puro e frio chão, desapiedadamente. Ao longo de quase cinco anos de sucessivos acampamentos em que se instalou o exército brasileiro - geralmente próximo aos ocupados pelos aliados argentinos e uruguaios - foram o habitat de milhares de homens e mulheres

\footnotetext{
${ }^{34}$ TAUNAY, A. E. Memórias. São Paulo: Melhoramentos, 1946,

${ }^{35}$ ARQUIVO NACIONAL. Cartas Particulares, cx. 813, pac. 3.

${ }^{36}$ CERQUEIRA, E. C. D. Op. cit., p. 304.

${ }^{37}$ OSÓRIO, J. L.; OSÓRIO FILHO, F. L. Op. cit., p. 290.
} 
de distintas classes sociais, profissionais, igualados pelas privações, pelos padecimentos da guerra e obrigados a se acostumar com a vida áspera e rude de campanha. Nos exércitos da época era um hábito que as famílias dos soldados, crianças, simples companheiras ou legítimas esposas, além de prostitutas, comerciantes e aventureiras civis, acompanhassem as tropas que marchavam para a guerra. ${ }^{38}$ Tratava-se de simples acampamentos, barracas e muitas vezes choupanas cobertas de capim, onde as tropas passavam dias, meses e até anos, às vezes tendo como abrigo somente capotes, chapéus e a sombra das árvores. Viviam sob indispensáveis regras disciplinares, muitas vezes quebradas, se desenvolvia uma vida complexa e variada. Eram acampamentos quase sempre afastados das cidades, montados em terrenos abertos ou rodeados de vegetação frondosa e mata fechada, próxima quando era possível, a cursos de água. Desenvolvia-se uma cotidiana instrução militar, a desafinadas bandas, a encontros junto ao fogo, aos jogos de azar, às longas conversações íntimas, às bebidas, aos amores confessados ou não, aos soldados com suas mulheres, casados ou não, movidos entre toques de clarim e sinais de alerta, às discussões políticas, literárias e artísticas, aos sonhos de glória de jovens oficiais, que muitas vezes se aborreciam com o passo lento do desenrolar da guerra e, alguns, com horror das batalhas.

A concentração de grande massa de combatentes e não combatentes exigiu a necessidade de garantir a ordem e a disciplina nos acampamentos do exército e nos navios da armada imperial. A ética tem regulado a conduta dos homens através de sua evolução histórica por meio de regras, normas e valores, estabelecendo estreito vínculo entre os conceitos morais e a realidade humana. Os chefes militares precisavam contar, a qualquer hora e em qualquer situação, com um grupo de soldados disciplinados e em condições de guerrear, sob um regime férreo, conscientes das graves sanções, algumas de aplicação imediata, a que estariam sujeitos, em caso de descumprimento dos seus regulamentos. Isso porque, diante de um inimigo, colocando em risco a própria vida e a de seus companheiros, tornou-se imperioso para os chefes militares que tivessem total controle sobre os seus exércitos. A soldadesca sempre original, cantarolava baixinho, enquanto marchava:

38 DOURADO, M. T. G. Mulheres comuns, senhoras respeitáveis: a presence feminine na Guerra do Paraguai. Campo Grande: EdUFMS, 2005, p. 23. 
Oh! Tu, que estás de guarda,

Não te faças de amarelo,

Que aí vem o sargento

Com a vara de marmelo ${ }^{39}$.

A questão que se coloca ao historiador, que tem por objetivo a reconstituição dos crimes e das práticas punitivas ocorridas nos acampamentos do exército e nas esquadras imperiais, é a de compreender por que havia um número significativo de casos de transgressões por parte tanto de simples soldados quanto de oficiais; por que muitos eram perdoados, não sendo punidos apesar das faltas cometidas, por que a justiça delineada através de artigos de guerra, decretos e leis não chegava de forma total aos campos de batalha e por que para um mesmo crime havia punições tão diferentes. $\mathrm{O}$ que desejo apontar e destacar é que as três forças armadas oficiais que atuaram na Guerra do Paraguai, quais sejam: exércitos de linha, guardas nacionais e voluntários da pátria, tinham origens em sua maior parte, em elementos não dotados de disciplina e ordem, oriundos de uma estrutura social não condizente com normas e regras tendo grandes dificuldades em se adaptar ao cotidiano do regime militar. Apesar de a Guarda Nacional ser considerada tropa de elite não se admitiu de forma passiva a liderança do exército, criando inúmeros empecilhos ao recrutamento mesmo durante os anos da guerra, devido às divergências entre autoridades civis (políticos) e militares prejudicando e retardando o combate ao invasor paraguaio.

Portanto, diante do árduo trabalho de instruir e disciplinar as instruções eram dadas de forma rigorosa e criteriosa na tentativa de organização do acampamento militar, mas a documentação analisada contesta essas versões, pois muitas vezes essas ordens e a própria legislação não eram obedecidas e cumpridas, consideradas letra morta, o que gerava grandes desentendimentos internos e externos ao longo dos cinco anos que durou a guerra. Do lado argentino também não era diferente. Ser oficial implicava optar por uma existência cheia de privações e sacrifícios, então, formar:

cuerpos de línea como soldados constitía uno de los castigos más graves e insoportables para los hijos del país. Com excepción de unos pocos voluntários

${ }^{39}$ QUEIROZ, M. I. P. O mandonismo local na vida política brasileira. São Paulo: Anhembi, n. 27, nov. de 1995. 
estimulados por el amor hacia la carrera de las armas o decididos a buscar el olvido de malos pasos y frustaciones mediante una existencia dura, la mayor parte de la tropa ubicada em la frontera o en las guarniciones había sido arreada por los jueces de paz y los camandantes militares en injustas levas. ${ }^{40}$

De fato, já em 1865, portanto, no início da guerra, o General Osório narrou que "todos os batalhões que se formaram depois da declaração da guerra, foram de homens que não conheciam a disciplina militar; n'este estado iam reunir-se ao exercito" ${ }^{41}$. Situação que continuou a perdurar nos anos seguintes. Em carta de 20 de julho de1866, de Corrientes escreveu o Conselheiro Otaviano ao General Osório que: "organizar, instruir e disciplinar um grande Exército, composto em sua quase totalidade de homens alheios à profissão das armas..."42 eram tarefas quase impossíveis. A noção de obediência passiva, fundamento da disciplina e da hierarquia nas organizações militares foi um ideal perseguido durante toda a guerra, principalmente por Caxias, que simbolizava o oficial disciplinado e disciplinador e cujo nome serviu de exemplo num dicionário nacional que a ele assim se refere "diz-se de, ou pessoa que, no exercício de sua função, exige dos subordinados o máximo rendimento no trabalho e extremado respeito às leis $\mathrm{e}$ aos regulamentos"43. Situações como essa levavam a outra: os crimes ocorridos durante a Guerra do Paraguai em acampamentos militares e navios da Armada estariam diretamente relacionados com a composição humana formada na maioria das vezes de forma compulsória.

No primeiro ano da guerra, noto através das fontes que, para organizar o exército, foi preciso introduzir desde as regras mais básicas e simples, com tudo por fazer. Um general em chefe que deveria ter a cabeça livre e descansada para pensar em planos de batalha e como vencer o inimigo, era obrigado a "ocupar-se de coisinhas, de bagatelas, por falta de quem os auxilie," 44 como a organização da ordem de marcha. Assim é que, em 2 de setembro de 1865, o General Manuel Luís Osório elaborou e mandou publicar as seguintes instruções sobre o modo de como deveriam ser feitas as marchas:

\footnotetext{
${ }^{40}$ DE MARCO, M. A. La Guerra del Paraguay. Buenos Aire: Planeta, 2003, p. 81.

${ }^{41}$ OSÓRIO,J. L.; OSÓRIO FILHO, F. L. Op. cit., p. 45.

${ }^{42}$ Idem, p. 267.

${ }^{43}$ HOUAISS, A. Pequeno dicionário enciclopédico. Rio de Janeiro: Larousse do Brasil, 1980, ${ }^{44}$ OSÓRIO, J. L.; OSÓRIO FILHO, F. L. Op. cit., p. 108.
} 
Ordem de marcha

O toque da alvorada é o de aprontar. A esse toque, desarmam-se as barracas, colocam-se os bois e cavalos nos diversos veículos e na artilharia, ensilham-se os cavalos e cargueiros, e os Quartéis-Mestres reúnem as bagagens e mulheres. As guardas do campo e ordenanças de infantaria e os piquetes recolhem-se a seus corpos, menos as guardas da Pagadoria e Principal. Esta marcha a retaguarda da última bateria. A bagagem marcha no flanco reverso da coluna, a distancia de 50 a 80 passos, se o terreno permitir, e nos passos e desfiladeiros passa a retaguarda das Brigadas a que pertençam. As cavalhadas marcharão ainda no flanco da bagagem a distância maior de 100 passos, e tocados de maneira que não se juntem tanto aos cavalos, que se estropem. Os Corpos e Brigadas guardam uns aos outros a distância de 24 passos, além da que deve ocupar a sua primeira facção. As Divisões guardam 100 passos de distância entre si, na marcha. O transporte segue a cauda da coluna e em primeiro lugar as carretas de munições de infantaria, tão reunido como o permittir a estrada. Seguir-se-a o Hospital; ficando para trás da Guarda da retaguarda o Commercio, que não se permitirá passar nenhum desfiladeiro sem que todo o Exercito o tenha passado ${ }^{45}$.

As narrativas clássicas de natureza memorialista, escritas para a posteridade e comprometidas com outras conjunturas nacionais, possibilitam informações preciosas sobre o cotidiano de um acampamento militar nas suas mais variadas vertentes. Apesar de alguns exageros em seus escritos, na visão do General Evangelista de Castro Dionísio Cerqueira, que combateu na guerra por cinco anos, a força militar no começo da guerra "era um exército de um povo descuidado, e constituído de soldados bisonhos." ${ }^{6}$ Declaração semelhante foi dada pelo General Osório que dizia, com abundância de fundamentos, que um exército bisonho, sem instrução, embora valente, numeroso, lançado ao inimigo sem critério nenhum, além de uma desgraça colossal para o País, representava verdadeira desumanidade, senão crime hediondo ${ }^{47}$. Também a esse respeito o General Caxias escreveu ao Ministro da Guerra, João Lustosa de Cunha, Marquês de Paranaguá, referindo-se aos anos anteriores à guerra, que, "por um conjunto de circunstâncias deploráveis, o nosso Exército contava sempre em suas

\footnotetext{
${ }^{45}$ Idem, p. 113.

46 CERQUEIRA, E. C. D. Op. cit., p. 21.

${ }^{47}$ SILVA, J. L. Op. cit., p. 21.
} 
fileiras grandes maioria de homens que a sociedade repudiava por suas péssimas qualidades." ${ }^{48}$

Em 28 de abril de 1869, Alfredo d'Escragnolle Taunay, em Diário do Exército, descreveu um panorama geral da situação dos soldados presos nos acampamentos militares: na região fronteira à barranca de Humaitá, existiam 230 presos dos quais 90 tinham respondido a um Conselho de Investigação, 46, ao Conselho de Guerra, 9, sentenciados à morte esperavam o resultado do último apelo previsto na lei, 1 expulso do exército que não podia ser solto pela necessidade da restituição de certa soma, provavelmente acusado de roubo e, finalmente, 92 presos estavam à espera da instauração dos processos que, ou se haviam extraviados ou nunca tinham sido instaurados. Entre estes últimos, ou seja, os 92 soldados presos deu-se o maior número de solturas, porque, acusados de crimes graves, como mortes, ferimentos, etc., estavam sem processo formal, e foram entregues à guarda do exército para que se procurassem, por informações nos Corpos, meios de regularizar o andamento dos papéis de acusação. Entretanto as dissoluções de muitos batalhões e as freqüentes transferências de praças de um para outro Corpo tornaram impossível tal resultado. Os acusados foram soltos, pelo princípio básico que não pode haver pena aquele cuja culpabilidade não poderia ser provada ${ }^{49}$.

Havia um enorme descompasso entre o que era fixado nas leis, o modo como os processos eram efetivamente encaminhados e as penalidades aplicadas. Muitas vezes, os oficiais que conduziam os processos conheciam a legislação militar de forma precária e terminavam por agir de forma parcial, o que comprometia o próprio princípio de justiça. Pela data citada posso concluir que ainda no final da guerra a justiça era lenta, precária e ineficiente, pois infratores que se achavam sob ação do Conselho de Guerra e do Conselho de Investigação, esperavam a sua longa deliberação, sendo dada uma ordem para que se procedesse com a maior urgência, trabalhando constantemente dois Conselhos, um com a presença do auditor formado, outro para os crimes leves, sem aquela autoridade. Essa situação gerava outra, que foi a forma e o local onde os presos aguardavam os julgamentos. A esse respeito, Taunay esclareceu:

48 DORATIOTO, F. F. M. Maldita Guerra: nova história da Guerra do Paraguai. São Paulo: Cia. das Letras, 2002, p. 111.

${ }^{49}$ TAUNAY, A. E. Diário do Exército, De Campo Grande a Aquidabã a Campanha da Cordilheira. São Paulo: Melhoramenos, 1958, v. III, p. 58. 
Sua Alteza oficiou ao General Polidoro acêrca de queixas, que têm chegado ao seu conhecimento, feitas por indivíduos que estiveram presos na guarda do exército de Assunção sobre o mau trato que aí receberam, ficando em muitos casos até expostos à cruel sêde pela maneira brutal com que se os tratara. Recomendado àquele general sindicância a tal respeito, renova as ordens anteriores para a formação e rápido andamento dos conselhos de guerra, cuja demora traz como conseqüência a acumulação de presos no pontão e na guarda, com prejuízo dos princípios da mais simples humanidade ${ }^{50}$.

A História da Justiça Militar no Brasil iniciou-se com a chegada da Família Real, em 1808, quando a cidade do Rio de Janeiro passou a ser sede da Coroa Portuguesa. A situação do país, de simples colônia, ainda que intitulada Vice-Reino, alterou-se profundamente e, por conseqüência direta dessas mudanças, fez-se necessária a mais completa reorganização do País. O Conselho Supremo Militar e de Justiça era o órgão máximo da justiça criado pelo príncipe regente, D. João, que julgava tanto os problemas administrativos da marinha e do exército (promoções, transferências, etc.) como infrações e crimes tipicamente militares (deserções, insubordinações, abandono de serviço, etc.) Ele era dividido em duas secções, o Conselho Supremo Militar e o Conselho de Justiça. O primeiro deles dava continuidade à tradição do antigo Conselho de Guerra de Lisboa, sendo regulado, dentre outros documentos, pelo Regimento de 22 de dezembro de 1643. Já o Conselho Supremo seguia uma tradição mais recente, fundado por D. Maria I, com decretos de 1777. Mas, além do Conselho Supremo Militar e de Justiça, a justiça militar da época era integrada por outras instituições: os conselhos de guerra, as juntas de justiça militar e as comissões militares ${ }^{51}$. A Constituição do Império do Brasil, outorgada em 25 de março de 1824, por D. Pedro I, estabelecia em seu artigo 102, capítulo II, atribuição XV, que cabia ao Imperador "prover de tudo, que for concernente à segurança interna, e externa do Estado". A defesa do Estado estava também prevista no Código Criminal do Império de 1830, mas não havia um código ou uma lei especialmente dedicada ao tema. Somente com a Constituição de 1934 a Justiça Militar foi vinculada ao Poder Judiciário

O Código Criminal do Império, de 16 de dezembro de 1830, ressalvava em seu artigo 308: "Este Código não compreende: $2^{\circ}$ - os crimes puramente

\footnotetext{
${ }^{50}$ Idem, p. 197.

${ }^{51}$ SEIXAS, A. M. A justiça militar no Brasil. Estrutura e funções. Dissertação (Mestrado). Campinas, 2002.
} 
militares, os quais serão punidos na forma da lei respectiva" ${ }^{52}$. Por isso, diante da necessidade de se criarem leis que atendessem a um estado de guerra que o país enfrentava, foram criados ainda no Império os Conselhos de Disciplina para verificar as deserções dos praças de pré; os Conselhos de Investigação para analisar atos criminosos em geral e deserção de oficiais de patentes, os Conselhos de Guerra, para julgar em primeira instância os crimes militares; o Conselho Supremo Militar, tribunal de segunda instância para julgamento dos referidos crimes, e as Juntas de Justiça Militar e os Conselhos para faltas disciplinares ${ }^{53}$.

Observa-se bastante indulgência por parte do imperador D. Pedro II que interferia nos processos, mandando, talvez porque soubesse da precariedade no cumprimento da lei, por exemplo, soltar 51 presos, em 28 de abril de1869, no Pontão Ana, no acampamento de Humaitá e mais 12 de Assunção. Todos eles estavam detidos sem haver possibilidade de se instaurar processo, pois não tinham culpas formadas e que, para o Imperador, os crimes eram de pouca importância e o tempo de prisão era castigo suficiente, pois alguns se achavam detidos desde 26 de janeiro, 25 de agosto e 15 de setembro de $1867 .{ }^{54}$ Portanto, não poucas vezes a decisão imperial substituiu os tribunais militares e a possibilidade de revisão das sentenças o que, para Michel Foucault, filósofo e historiador francês e um precioso analista do poder que afirma onde há poder e saber há resistência, o Imperador deveria ser aquele que pune, mas jamais o que age sob o signo da vingança ${ }^{55}$.

Inúmeras dificuldades envolviam o pleno funcionamento da Justiça durante a guerra, como por exemplo: o deslocamento dos acusados ao local de julgamento e as formalidades jurídicas que regiam o processo como no caso de não haver no Código Militar punição para alguns crimes. O Decreto 3499, de 8 de julho de 1865, criou provisoriamente duas Juntas de Justiça Militar, uma na Província de São Pedro, do Rio Grande do Sul e outra na de Mato Grosso que:

[...] funcionarão no lugar que pelo governo será designado, cada uma dessas Juntas sera composta de 1 Presidente, que será o Presidente da respectiva

${ }^{52}$ BRASIL. Código criminal do Império, 1830.

${ }^{53}$ ROMEIRO, J. Um velho advogado na justice militar. Belo Horizonte; Imp. Official, 1962.

${ }^{54}$ TAUNAY, A. E. Diário..., op. cit., p. 29.

55 FOUCALT, M. Vigiar e punir. Petrópolis: Vozes, 1987. 
Província e de 6 membros, sendo 3 militares e 3 magistrados ou bacharéis formados em direito designado pelo governo e interinamente pelo respectivo Presidente, os membros militares poderão ser oficiais generaes ou superiores de qualquer das classes do exercito ${ }^{56}$.

Uma carta de Inocêncio Velozo Pederneiras ao Almirante Visconde de Tamandaré, datada de 3 de dezembro de 1876, imediatamente depois de terminada a guerra, mas que traduz a continuação das dificuldades encontradas em se punirem alguns casos, critica o sistema militar de julgamento de faltosos, referindo-se ao caso de seu ajudante de ordens que cometeu "indisciplina e desobediência" às ordens, tendo que responder ao código criminal ordinário ${ }^{57}$. Uma das medidas postas em prática para resolver esses obstáculos, foi a decisão do Governo Imperial criar, em 1866, uma Junta de Justiça Militar que passaria a funcionar diretamente no teatro de operações, junto ao exército quando se estabeleceu pela primeira vez um órgão da Justiça Militar especial para atuar fora do território brasileiro. Ainda assim, as faltas cometidas pelos militares durante a guerra nem sempre eram levadas à instância jurídica. Muitas delas eram resolvidas no próprio local em que eram cometidas e aplicadas as penalidades, segundo o arbítrio do comandante do infrator. Portanto, a administração da justiça estava confiada à Junta de Justiça Militar que decidia, em segunda e última instância, as sentenças dos Conselhos de Guerra, exceto nos casos de pena de morte e estava baseadas nos Códigos do Conde de Lippe, os conhecidos e famosos Artigos de Guerra ${ }^{58}$, título de um dos capítulos dos Regulamentos de Infantaria e cavalaria. Foi a primeira legislação penal militar brasileira, do ano de 1763 e formulada pelo oficial alemão, Wilhelm Schaumburg-Lippe, a pedido do Marquês de Pombal, no governo de D. José I, de Portugal, tendo por objetivo a reestruturação do exército português e adotado no Brasil no século XVIII. As disposições contidas nesses artigos constituíram, até a publicação do novo código de justiça militar em 1870, a mais importante das leis penais do nosso exército.

${ }^{56}$ BRASIL. Colleções das leis do Império do Brasil. Rio de Janeiro: Typ. Nacional, 1865, tomo XXV, parte 1, p. 309.

${ }^{57}$ ARQUIVO DA MARINHA. Arquivo do Almirante Tamandaré, Livro IX, doc. 838, p. 46.

${ }^{58}$ CENTRO DE ESTUDOS DE DIREITO MILITAR. Revista Direito Militar. Santa Catarina, v. 52, p. 28-30. 
Extremamente rigorosos são os Artigos de Guerra. Destacam-se 13 deles, portanto $44,82 \%$ em um total de 29 , penalidades que levavam à morte, sendo 0 mais rigoroso e temido o artigo o $5^{\circ}$, pois o autor do delito aí prescrito seria punido com a execução imediata, sem qualquer julgamento, pela espada do oficial mais próximo. Mas segundo as fontes analisadas, em nenhum caso foi constatada a aplicação desse artigo da lei. A obediência e respeito a todos os oficiais é um elemento intrínseco na carreira militar, reforçada no Código apenas para que se buscasse a idéia de um exército uno, mesmo que na época houvesse oficiais de diversas nacionalidades. 